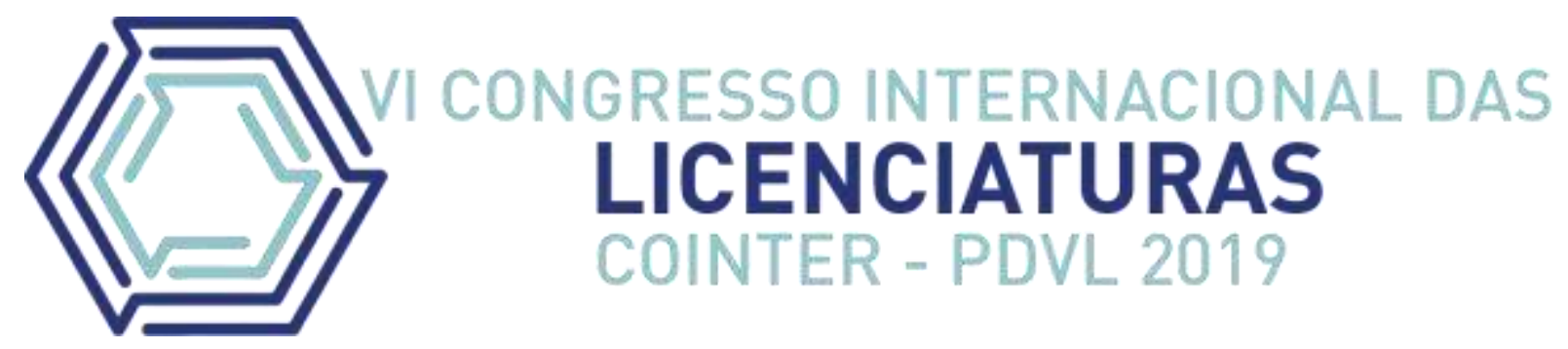

\title{
PROJETO LABORATÓRIO NA ESCOLA: BUSCANDO MELHORAR O ENSINO DE CIÊNCIAS
}

\section{PROYECTO DE LABORATORIO EN LA ESCUELA: BUSCANDO MEJORAR LA ENSEÑANZA DE CIENCIAS}

\section{LABORATORY PROJECT AT SCHOOL: SEEKING TO IMPROVE SCIENCE TEACHING}

\author{
Apresentação: Comunicação Oral \\ Wallace Figuerêdo Barboza ${ }^{1}$; Andreza Maria Angelim Callou ${ }^{2}$; Dan Vitor Vieira Braga ${ }^{3}$ \\ Márcia Queiroz de Lucena ${ }^{4}$
}

DOI: https://doi.org/10.31692/2358-9728.VICOINTERPDVL.2019.0009

\section{Resumo}

O Ensino de ciências tem um papel importante para o entendimento de como funciona o mundo, mas devido as dificuldades que os alunos têm de compreender os assuntos, acaba acarretando uma série de problemas no processo ensino aprendizagem, já que o professor também não percebe algumas deficiências pedagógicas que interferem no ensino. O programa Residência Pedagógica do Núcleo Biologia tem como objetivo analisar, durante a fase de ambientação, o PPP e seus eixos/princípios norteadores e compará-lo à prática pedagógica da escola. Após a análise da escola, será desenvolvido um projeto de intervenção, baseado no que foi visto junto ao professor de ciências como uma das principais dificuldades, para melhorar o ensino de ciências. A pesquisa foi desenvolvida na cidade de Salgueiro - PE, Escola Municipal Dom Malan com alunos das séries finais do Ensino Fundamental. Para análise do espaço escolar, foram usados cadernos etnográficos para anotações de dados e também foram fotografados todo o ambiente escolar para em seguida definir uma intervenção. Após a análise do PPP e de toda a estrutura interna da escola, foi visto que não havia um espaço adequado para aulas práticas e experimentais. Foi decidido elaborar um espaço na escola para construção de um minilaboratório didático de ciências para que os alunos possam manipular objetos científicos, elaborar maquetes e fazer experimentos, entre outras coisas. O laboratório está em processo de construção e já foram acrescentados alguns materiais didáticos como caixas entomológicas e organográficas. Contudo, como o laboratório está no início do processo de construção, ainda não aconteceu aulas nele, mas pode-se entrar em contato com o coordenador do Curso de Licenciatura em Ciências Biológicas da Faculdade de Ciências Humanas do Sertão Central

\footnotetext{
${ }^{1}$ Licenciatura em Ciências Biológicas, FACHUSC, wallace_barboza1990@outlook.com

${ }^{2}$ Licenciatura em Ciências Biológicas, FACHUSC, andrezaange1997@gmail.com

${ }^{3}$ Mestre em Gestão e Políticas Ambientais, FACHUSC, bragadvv@gmail.com

${ }^{4}$ Graduada em Pedagogia, URCA, Márcialq74@gmail.com
} 
(FACHUSC) do município de Salgueiro, onde foi solicitado o laboratório da faculdade para o desenvolvimento de uma aula prática de microscopia. Nessa aula, os residentes tiveram a oportunidade de elaborar e conduzir uma parte da aula, os alunos tiveram a oportunidade de ver as células vegetais em microscópio óptico, bem como a analisar as estruturas florais no estereomicroscópio e observar uma parte do acervo que o laboratório da faculdade dispõe. Conclui-se que pelo que se notou dos alunos, eles adoraram a aula de microscopia no laboratório da faculdade, puderam ver as células das plantas e tiraram várias dúvidas sobre o assunto. Por fim o projeto de intervenção laboratório na escola irá ajudar o professor em suas aulas, bem como facilitar a aprendizagem dos alunos.

Palavras-Chave: Laboratório, Ensino, Ciência, Práticas, Experimentos.

\section{Resumen}

La educación científica tiene un papel importante en la comprensión de cómo funciona el mundo, pero debido a las dificultades que tienen los alumnos para comprender los problemas, termina causando una serie de problemas en el proceso de enseñanza-aprendizaje, ya que el profesor tampoco percibe algunas deficiencias. que interfieren con la enseñanza. El Programa de Residencia Pedagógica de Núcleo Biologia tiene como objetivo analizar, durante la fase de establecimiento, el PPP y sus principios / ejes rectores y compararlo en la práctica pedagógica de la escuela. Después del análisis de la escuela, se desarrollará un proyecto de intervención, basado en lo que se vio junto al maestro de ciencias como una de las principales dificultades, para mejorar la enseñanza de la ciencia. La investigación se llevó a cabo en la ciudad de Salgueiro - PE, en la escuela Dom Malan con alumnos de primaria de los últimos grados. Para el análisis del espacio escolar, se utilizaron cuadernos etnográficos para anotaciones de datos y también se fotografió todo el entorno escolar para definir una intervención. Después de analizar el PPP y toda la estructura interna de la escuela, se vio que no había espacio adecuado para las clases prácticas y experimentales. Se decidió elaborar un espacio en la escuela para construir un laboratorio improvisado para que los estudiantes pudieran manipular objetos científicos, elaborar modelos y realizar experimentos, entre otras cosas. El laboratorio está en proceso de construcción y ya se han agregado algunos materiales didácticos, como cajas entomológicas y organográficas. Sin embargo, desde el laboratorio se encuentra al principio del proceso de construcción, aún no ha sucedido lecciones en ella, pero puede ponerse en contacto con el coordinador de la Licenciatura en Ciencias Biológicas en la Facultad de Humanidades de las Ciencias Hinterland Central (FACHUSC) del municipio de Salgueiro, donde se le pidió al laboratorio de la universidad que desarrollara una práctica lección de microscopía. En esta clase los residentes tuvieron la oportunidad de elaborar y dirigir una parte de la clase, los estudiantes tuvieron la oportunidad de ver las células vegetales en el microscopio óptico, así como analizar las estructuras florales en el estereomicroscopio y observar una parte de la colección que el laboratorio de la facultad disponible Resulta que, según lo observado por los estudiantes, les encantó la lección del microscopio en el laboratorio de la universidad, pudieron ver las células de las plantas y tenían varias dudas sobre el tema. Finalmente, el proyecto de intervención en el laboratorio de la escuela ayudará al maestro en sus clases y facilitará el aprendizaje de los alumnos.

Palabras Clave: Laboratorio, Docencia, Ciencia, Prácticas, Experimentos. 


\begin{abstract}
Science education has an important role in understanding how the world works, but due to the difficulties students have to understand the issues, it ends up causing a series of problems in the teaching-learning process, since the teacher also does not perceive some deficiencies that interfere with teaching. The Pedagogical Residence Program of Núcleo Biologia aims to analyze, during the setting phase, the PPP and its guiding principles / axes and to compare it in the pedagogical practice of the school. After the analysis of the school, an intervention project will be developed, based on what was seen next to the science teacher as one of the main difficulties, to improve the teaching of science. The research was carried out in the city of Salgueiro - PE, at Dom Malan School with elementary students from the final grades. For the analysis of the school space, ethnographic notebooks were used for data annotations and the entire school environment was also photographed to define an intervention. After analyzing the PPP and the entire internal structure of the school, it was seen that there was no adequate space for practical and experimental classes. It was decided to elaborate a space in the school to construct an improvised laboratory so that the students could manipulate scientific objects, elaborate models and to make experiments, among other things. The laboratory is in the process of construction and some didactic materials such as entomological and organographic boxes have already been added. However, as the laboratory is at the beginning of the construction process, there have not yet been any classes in it, but you can contact the coordinator of the Biological Sciences Degree Course of the Faculty of Human Sciences of the Central Hinterland (FACHUSC) of the municipality of Salgueiro, where the college laboratory was asked to develop a practical microscopy lesson. In this class the residents had the opportunity to elaborate and to conduct a part of the class, the students had the opportunity to see the vegetal cells in optical microscope, as well as to analyze the floral structures in the stereomicroscope and to observe a part of the collection that the laboratory of the faculty available. It turns out that from what was noticed by the students, they loved the microscopy lesson in the college laboratory, they could see the plant cells and they had several doubts on the subject. Finally, the intervention project in the school laboratory will help the teacher in their classes as well as facilitate the students' learning.
\end{abstract}

Keywords: Laboratory, Teaching, Science, Practices, Experiments.

\title{
Introdução
}

Como ponto de partida é preciso fazer uma análise profunda sobre as condições escolares para que haja um ensino público de qualidade (PANIZZOLO et al., 2012). O Estágio Curricular é uma ferramenta para desenvolver experiência fundamental para a formação de qualidade de futuros professores, mas muitas vezes se mostram como experiências frustrantes para os estudantes quando se deparam com os problemas da profissão (POLADIAN, 2014).

Para Hahn e Machado (2006), o Projeto Político Pedagógico (PPP) é objeto de estudo tanto para professores como pesquisadores, na busca de um avanço na qualidade de ensino, e a 
ausência de um PPP impossibilita o desenvolvimento educacional de toda e qualquer escola.

Segundo Natividade e Medeiros (2014), atualmente fala-se muito sobre gestão democrática e o PPP na educação, porém na prática, as escolas não realizam com satisfação uma discussão sobre essa temática assim como não separam um tempo para elaboração e implementação do seu PPP.

A metodologia tradicional ainda está enraizada nas escolas, pois ela tem sido ao longo do tempo, o pilar para outros métodos de ensino apresentando grande significância no processo ensino e aprendizagem. É nesse método que o professor fica mais confortável e adquire melhor controle sobre a turma (CARDOSO, 2013). Serafim (2001), ainda destaca que essa metodologia faz com que os alunos pouco se manifestem e são condicionados a dar a "resposta correta", e não a discutir e levantar hipóteses.

O Ensino de Ciências tem um papel importante para o entendimento de como funciona o mundo, mas devido as dificuldades que os alunos têm de compreender os assuntos, acaba acarretando uma série de problemas no processo ensino aprendizagem, já que o professor também não percebe algumas deficiências pedagógicas que interferem no ensino (SANTOS et. al, 2013). Corroborando com Serafim (2001) que destaca a dificuldade do aluno em relacionar a teoria com a realidade a sua volta. Considerando que a teoria se embasa em conceitos, que são abstrações da realidade.

As atividades práticas podem facilitar o processo ensino e aprendizagem, favorecendo os alunos com modos de pensar e desenvolver novas atitudes interligando tecnologias, ciência, sociedade e o ambiente onde vivem, visando o ensino de ciências e aproximando à sua realidade (CACHAPUZ et al., 2005). E de acordo com os Planos Curriculares Nacionais (PCN), as aulas práticas favorecem o ensino de ciências valorizando atitudes que podem ser desenvolvidas durante as atividades como forma de incentivo, respeitando opiniões diferentes e a busca de dados por meio da investigação (BRASIL, 2000).

Andrade e Massabni (2011), afirmam que a escola e o professor têm o compromisso de dar a oportunidade aos seus alunos a terem aulas práticas durante a formação dos mesmos.

Cruz (2008), sugere aos professores usarem sua criatividade, utilizar materiais de baixo custo ou recicláveis a fim de oferecer aulas mais atrativas no que tange a experimentação.

Visando as dificuldades que existem no ensino de ciências, o programa Residência Pedagógica do Núcleo Biologia tem como objetivo analisar, durante a fase de ambientação, o PPP e seus eixos/princípios norteadores e compará-lo na prática pedagógica da escola 
observando como são as aulas de ciências nas séries finais do ensino fundamental bem como analisar o ambiente escolar e se pode ter potencial e dificuldades para o ensino diferencial de ciências (estrutura da sala, escola, laboratório, espaços abertos, arborização/jardinagem, etc.) e também observar e analisar o perfil dos alunos e a formação e metodologias usadas pelos professores. Após a análise da escola, será desenvolvido um projeto de intervenção, baseado no que foi visto junto ao professor de ciências como uma das principais dificuldades, para melhorar o ensino de ciências.

\section{Fundamentação Teórica}

Segundo Camargo et al. (2015), as pesquisas vêm aumentando ao longo do tempo sobre o ensino de ciências no fundamental, objetivando um suporte aos professores e a ampliação do conhecimento para um ensino de qualidade.

Para Bizzo (2009), o ensino de ciências possibilita a compreensão e o entendimento do mundo, contribuindo para formação de futuros cientistas. $\mathrm{O}$ autor também enfatiza como ponto importante o entendimento do conhecimento científico e sua importância na formação dos discentes.

Catelan e Rinaldi (2018), ressaltam que as atividades experimentais são estratégias didáticas que contribuem para o ensino e aprendizagem na sala de aula. Desde a década de 60 as tentativas para melhorar o ensino se baseiam em aulas experimentais.

A experimentação no ensino de ciências vem sendo debatida intensamente entre os pesquisadores da área de educação em ciências nas últimas décadas e apontada como importante recurso no desenvolvimento de saberes conceituais, procedimentais e atitudinais (GALIAZZI et al., 2001).

Sabendo disso Caporalin (2014), afirma que é de suma importância, que desde a formação, o professor tenha a perspectiva de possibilitar oportunidades onde os alunos participem de atividades práticas e experimentais, possibilitando a aproximação dos discentes ao conhecimento científico e ampliando suas visões de mundo.

É importante salientar a importância das atividades práticas, dentre elas podemos citar como essenciais para o ensino de ciência no fundamental as aulas de laboratório onde pode-se ter experimentações e manipulações de materiais, pesquisas, aulas em campo, entre outras (ANDRADE; MASSABNI, 2011). Essas atividades tem um cunho prático em comparação com aulas que só exploram o teórico das ciências, quanto maior o envolvimento dos alunos, melhor 
o seu desempenho e aprendizado (MORAES; ANDRADE, 2010).

Alguns autores como Silva e Neves (2006) e Ataíde (2010) descrevem a importância das atividades experimentais no currículo e outras metodologias que estão renovando o ensino de ciências e biologia.

Segundo Borges (2002), os estudantes devem conhecer alguns dos principais produtos usados na Ciência, entender como o método cientifico é usado pelos cientistas para o desenvolvimento de novos conhecimentos e como ela é importante para transformar o mundo.

Sabe-se hoje que os alunos necessitam desde cedo ter contato com aulas em laboratórios de ciências em suas respectivas escolas, para que possam aprender manipular os objetos de experimentação e observação do laboratório (ZIMMERMANN, 2005).

$\mathrm{Na}$ atualidade, é notório que a falta de laboratório para a realização de aulas práticas é um dos principais problemas enfrentados pelos professores. Porém algumas escolas que possuem esse espaço, sofrem com a falta de recursos e materiais. (SOUSA, et al. 2016).

Sob a perspectiva de Psillos e Niedderer (2002), a maior parte do tempo dedicado as aulas em laboratório é utilizada para manipulação de aparatos e hoje acredita-se que é necessário haver aulas experimentais a partir de questões investigativas constituindo problemas reais e desafiadores.

\section{Metodologia}

A presente pesquisa contou com o fomento da CAPES, através do Programa Residência Pedagógica e foi desenvolvida na cidade de Salgueiro - PE (Figura 1), na Escola Municipal de Referência Dom Malan.

Figura 1 - Localização geográfica da área de estudo. Fonte: Modificado de Wikipédia, 2019.

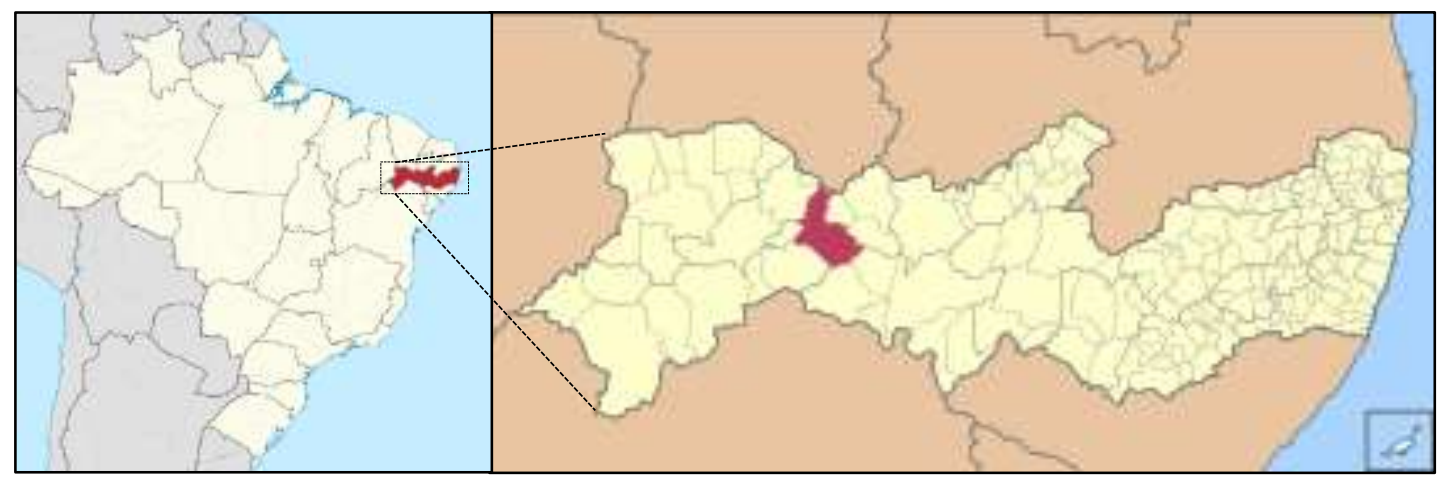

A escola integra a rede municipal de ensino e recebe alunos das séries finais do Ensino Fundamental. As análises estão sendo desenvolvidas desde agosto de 2018 e a intervenção pedagógica terminará em janeiro de 2020, sendo divididas em duas fases: a primeira de 
observação e análise (concluída em março de 2019) e a segunda com o projeto de intervenção (iniciada em abril de 2019).

Para análise do espaço escolar, foram usados cadernos etnográficos para anotações de dados da estrutura da escola, perfil dos alunos e professor, bem como o quadro de funcionários da escola. Também foram fotografados todo o ambiente escolar, espaços interno e externo à escola, para em seguida, analisar a potencialidade destes espaços para o ensino de ciências. Por fim, foi definida uma intervenção pedagógica que vise a inovação no ensino de Ciências na Escola Campo. Foi escolhida a construção de um minilaboratório didático na escola para desenvolvimentos de aulas práticas, experimentais e investigativas.

\section{Resultados e Discussão}

A Escola de Referência Dom Malan possui uma boa estrutura e espaçosa, sendo bastante arborizada. Atende alunos de diversas localidades da zona urbana e rural de Salgueiro. Durante as aulas, foi observado que os alunos são bem agitados, o que pode dificultar o processo de ensino e aprendizagem. Com relação ao docente de Ciências, ele é licenciado na área da disciplina, possuindo Licenciatura Plena em Ciências Biológicas. Ao acompanhar as aulas de Ciências, foi possível perceber que ele é bastante paciente com os alunos, mas um pouco rigoroso quando necessário pra manter o domínio da sala. Desta forma, evita-se dispersão dos alunos durante a aula.

O PPP da escola foi elaborado no ano de 2017 e tem como diretriz o trabalho pedagógico é norteado pelos seguintes eixos: 1. Crença de que todos podem aprender, valorizando a cooperação, o trabalho em equipe e ajuda mutua. 2. O ensino será ministrado conforme os valores de respeito, solidariedade, disciplina e coletividade; 3. Todas as ações fundamentadas em postura justa, coerente, valorizando o respeito e o diálogo, confiança e credibilidade. 4. Ao aluno, é reservado o papel de protagonista do seu processo de aprendizagem, sendo sujeito que experimente dúvida, analisa, erra, reconstrói, e, finalmente aprende e consolida conhecimento.

. Segundo Veiga e Resende (1998), ao se referir ao Projeto Político Pedagógico, fica claro que é tarefa da escola, construí-lo, executá-lo e avalia-lo e deve contemplar a questão da qualidade de ensino. Fato não observado na escola campo com relação o papel do aluno, já que observou-se que em se tratando da disciplina de Ciências, o aluno não tem muito interesse nesse tipo de conteúdo. Para a maioria deles termos científicos e definições não têm o menor significado, apenas servem para decorar para a prova chegando a desenvolver desinteresse a 
todo este conhecimento e a desvalorizar suas reais curiosidades acerca do conteúdo.

A escola possui, em termos de estrutura, uma horta (Figura 2), uma sala de vídeo, uma sala de atendimento educacional, uma biblioteca, uma quadra, 14 salas de aula, um depósito, dois banheiros, uma cozinha, um refeitório, um auditório. No quadro docente, possui apenas um professor de Ciências e no quadro discente 91 alunos de Zona Rural e 468 da Zona Urbana totalizando em 559 alunos.

Figura 2 - Ambientes pedagógicos externos à sala de aula presentes na Escola Municipal Dom Malan. A. Horta; B. Pátio. Fonte: Própria.

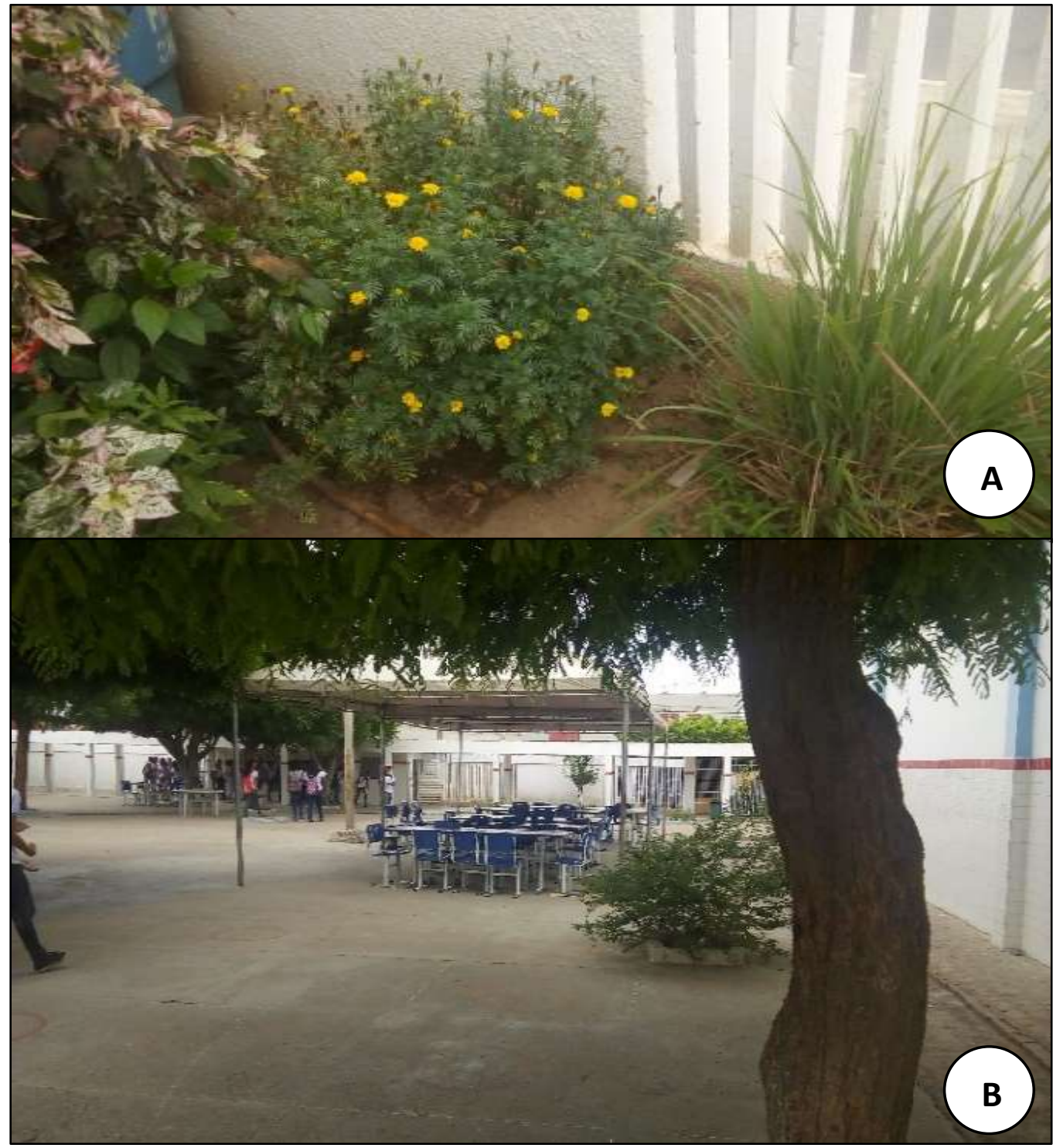

As aulas de ciências são através de texto escrito no quadro, livros e vídeo aulas através de projetores que de vez em quando é usado, ou seja, um ensino tradicional onde apena o conteúdo é transmitido aos alunos. 
Apesar de não haver laboratório na escola, possui ambientes abertos para trabalhar com aulas práticas e experimentais, o que não foi observado durante o tempo de estágio. Zimmermann (2005), afirma que os alunos necessitam, desde cedo, ter contato e participar de aulas em laboratórios de ciências em suas respectivas escolas, para saber como interagir com os materiais desses espaços.

Figura 3 - Ambiente interno da escola Dom Malan. A. bebedouro; B. quadra e depósitos. Fonte: Própria.

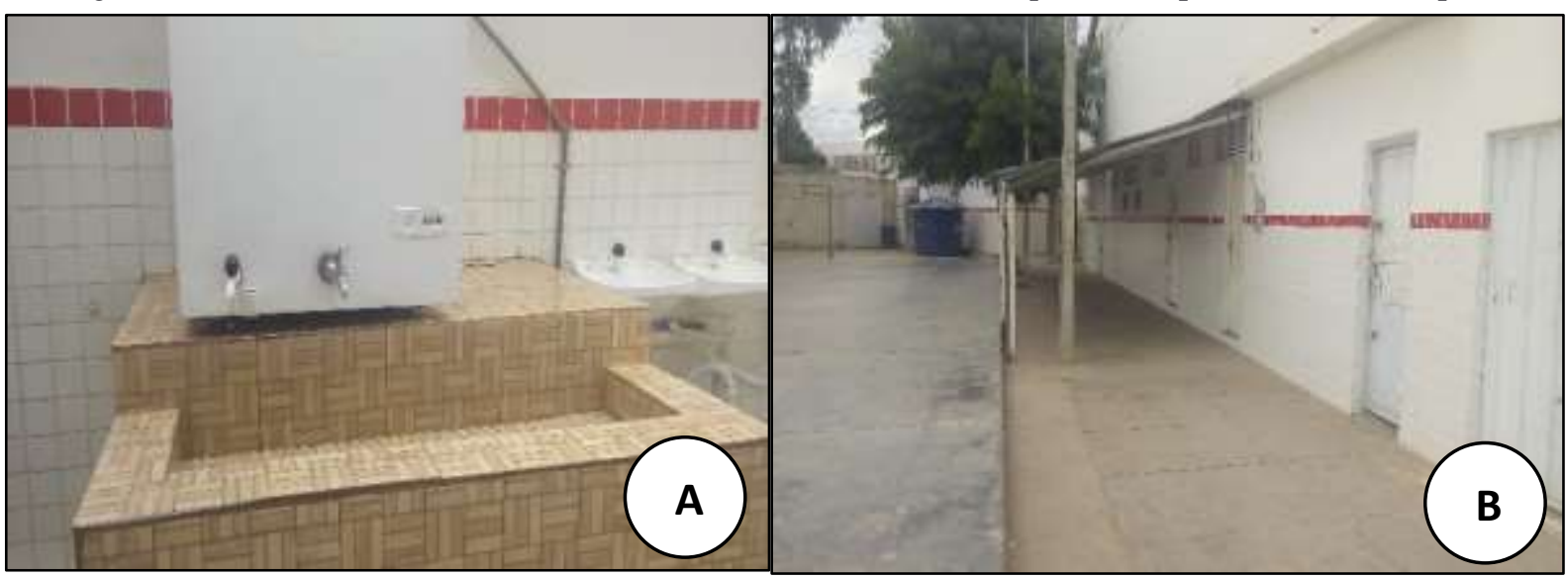

O ambiente externo da escola possui alguns pontos de comércio e um centro religioso. O único local possível com potencial pedagógico para ser explorado nas aulas de Ciências no ambiente externo à escola seria o riacho canalizado localizado no centro da avenida na lateral sul da escola. ao lado onde poderia dar aula sobre saneamento básico.

Após a análise do PPP e de toda a estrutura interna da escola, foi visto que não havia um espaço adequado para aulas práticas e experimentais, como um laboratório de ciências. Vendo isso como uma das principais dificuldades levantadas pelo professor responsável pela disciplina, foi decidido implantar um minilaboratório didático para que os alunos possam manipular objetos científicos, elaborar maquetes e fazer experimentos. Segundo Cardoso (2013), as atividades práticas tornam o aprendizado mais significativo e é através dela que os alunos querem aprender mais, no entanto para que aconteça com eficácia, é necessário a utilização de diferentes estratégias para que o processo de ensino aprendizagem ocorra com fluidez.

O laboratório (Figura 4) está em processo de implantação e já foram acrescentados alguns materiais didáticos como caixas entomológicas e organográficas (morfologia floral e foliar), onde os alunos poderão ter contato com esses instrumentos pedagógicos. O intuito é fazer com que os alunos usufruam do espaço para atividades práticas e experimentais com 
intermédio do professor e dos residentes. Além disso, possam desenvolver seus próprios instrumentos didáticos para serem empregados nas aulas de ciências e também. Este espaço pedagógico servirá como meio de "desmistificar" o ensino de ciências da mente dos alunos que o visam como um conteúdo chato e difícil, ou seja, despertar o interesse dos alunos ao conhecimento científico e entender como ele pode transformar o mundo.

Figura 4 - Espaço onde está em processo de construção o laboratório da escola Dom Malan. Fonte própria

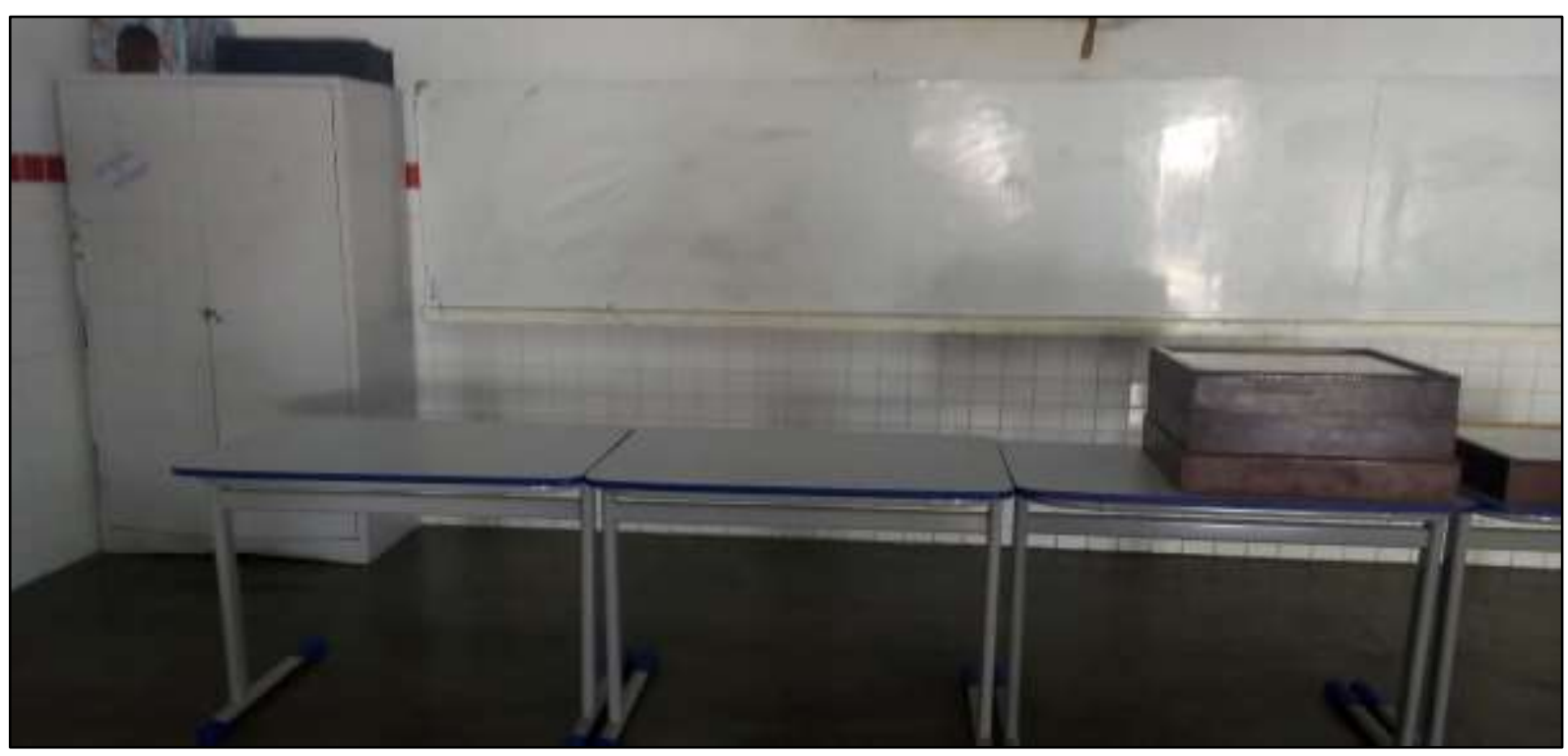

Figura 5 - Caixas dos materiais didáticos do laboratório em construção na escola Dom Malan. A. caixa entomológica; B. caixa organográfica. Fonte própria

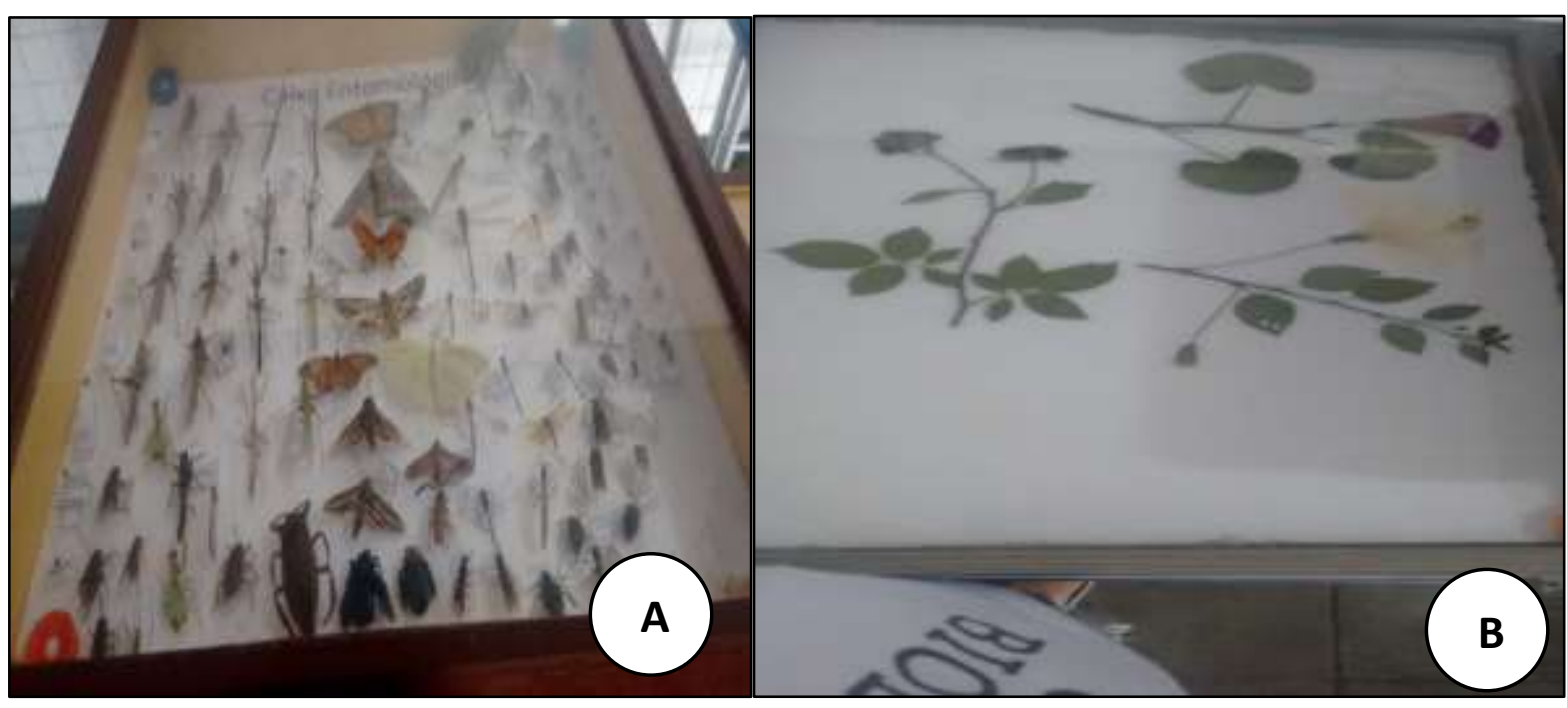

Como o laboratório está no início do processo de implantação, ainda não aconteceu aulas nele, mas pôde-se entrar em contato com o coordenador do Curso de Licenciatura em 
Ciências Biológicas da Faculdade de Ciências Humanas do Sertão Central (FACHUSC) do município de Salgueiro, onde foi solicitado o laboratório da faculdade para o desenvolvimento de uma aula prática de microscopia. Nessa aula, os residentes tiveram a oportunidade de planejar, elaborar e ministrar a aula prática para os alunos do $7^{\circ}$ ano do Ensino Fundamental, junto com o docente da escola e docentes da FACHUSC.

Nessa aula prática foram vistas as normas de segurança de um laboratório, onde puderam conhecer alguns Equipamentos de Proteção Individual (EPI) como luvas, máscaras, jaleco, bem como Equipamentos de Proteção Coletiva (EPC). Em seguida, eles tiveram a oportunidade de ver as células vegetais em microscópio óptico, bem como a analisar as estruturas florais no estereomicroscópio e observar uma parte do acervo didático que o laboratório da FACHUSC dispõe. Após o término da aula os alunos falaram suas opiniões e do que sentiram quando tiveram uma aula diferente do que estão acostumados e por unanimidade todos gostaram e estavam ansiosos para mais aulas práticas.

Figura 6 - Aula de microscopia com alunos do $7^{\circ}$ ano do fundamental na FACHUSC. Fonte Própria

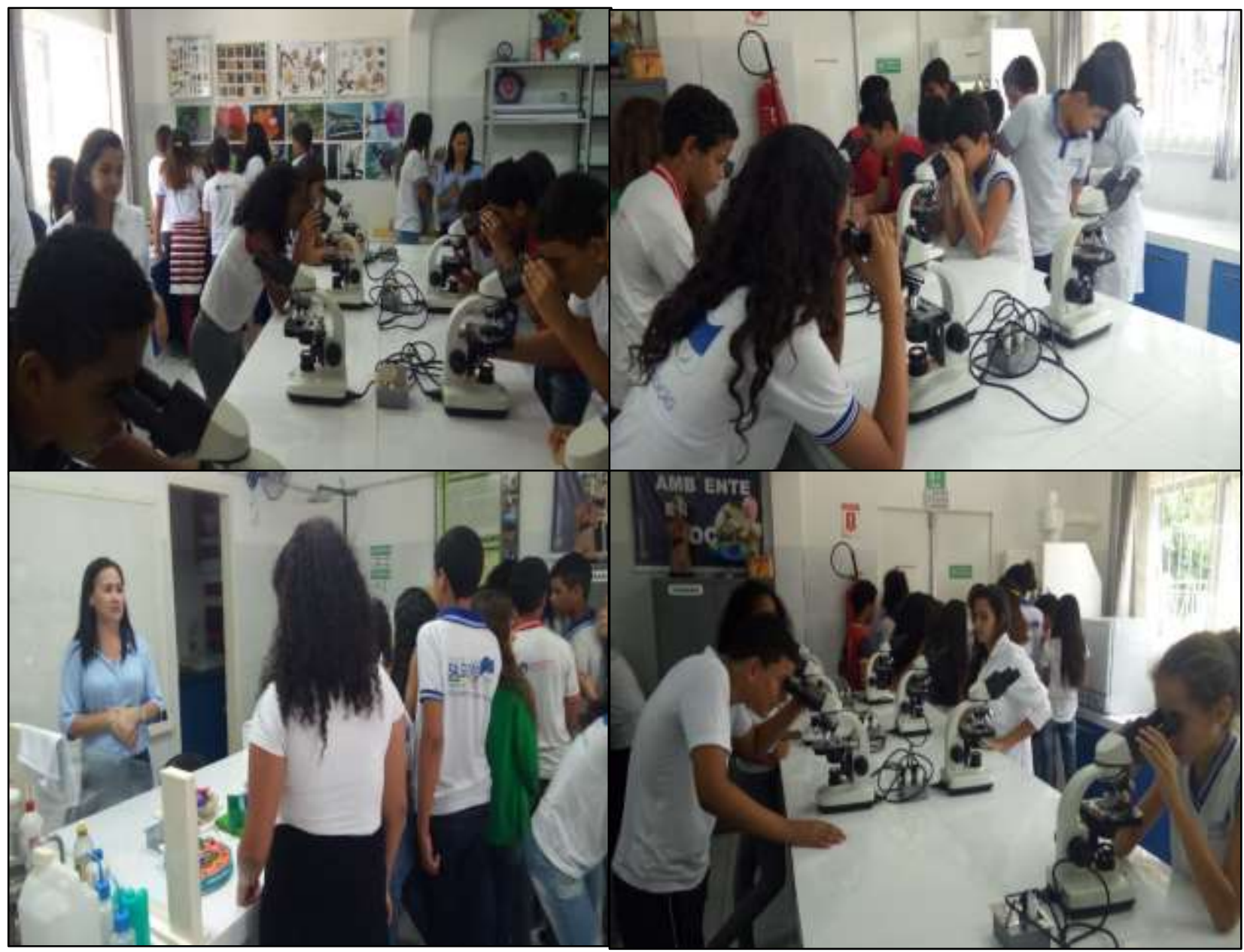




\section{Conclusões}

Conclui-se que a escola campo, em parte, cumpre o que está no Projeto Político Pedagógico e que a metodologia usada pelo professor nas aulas da disciplina de Ciências pode ser melhorada, usando métodos não tradicionais como aulas práticas e experimentais e até mesmo o ensino por investigação. Fato externado pelos alunos que ficaram extremamente motivados após a aula de microscopia no laboratório da faculdade. Por fim, o projeto de intervenção no minilaboratório da escola irá ajudar o professor em suas aulas, bem como facilitar a aprendizagem dos alunos.

O Programa de Residência Pedagógica tem como foco o avanço na formação dos futuros professores; reforçar o papel formador da escola e dos professores experientes e acrescentar uma boa qualidade ao processo formativo dos residentes, fazendo-o com que saiam formados em área de conhecimento, metas que estão sendo vivenciada diariamente pelos residentes nesta escola campo.

\section{Referências}

ANDRADE, M. L. F; MASSABNI, V. G. O desenvolvimento de atividades práticas na escola: Um desafio para professores de Ciências. Ciência \& Educação, v.17, n.4, p. 835-854, 2011.

ATAIIDE, M.C.E.S. Experimentos que geram rejeitos químicos com metais pesados em escolas da educação básica. 2010. 147 f. Dissertação (Mestrado em Ensino de Ciências e Matemática) - Universidade Federal do Rio Grande do Norte, Rio Grande do Norte, 2010.

BIZZO, Nelio. Ciências: fácil ou difícil?. São Paulo: Biruta, 2009. 158 p.

BRASIL. MINISTÉRIO DA EDUCAÇÃO E CULTURA. Secretaria de Educação Fundamental. Parâmetros Curriculares Nacionais: Ciências Naturais. 2. ed. Rio de Janeiro: DP\&A, 2000.

BORGES, A.T. (2004). Novos rumos para o laboratório escolar de ciências. Cad. Bras. Ensino Física, 21, 9-30. Disponível em: https://periodicos.ufsc.br/index.php/fisica/article/view/6607. Acesso em 20 jul. 2019.

CACHAPUZ, A. PENA, A. V. CARVALHO, A. M. P. PEREZ, G. PRAIA, J. A necessária renovação do ensino das ciências. São Paulo: Cortez, 2005.

CAMARGO, N. BLASZKO, C. E. UJIIE, N. T. O ensino de ciências e o papel do professor: concepções de professores dos anos iniciais do ensino fundamental. Paraná in: Anais... XII CONGRESSO INTERNACIONAL DE EDUCAÇÃO - EDUCERE. 2015. Disponível em: https://educere.bruc.com.br/arquivo/pdf2015/19629_9505.pdf. Acesso em 22 jul. 2019.

CARDOSO, F.S. O uso de atividades práticas no ensino de ciências: a busca de melhores resultados no processo ensino aprendizagem. Monografia para conclusão de curso de 
graduação em ciências biológicas no Centro Universitário UNIVATES. 2013.

CAPORALIN, C.B. A facilitação do processo ensino-aprendizagem de Química por sua experimentação. 2014. p. 49. Monografia (Especialização em Ensino de Ciências). Universidade Tecnológica Federal do Paraná, Medianeira, 2014

CATELEN, A.C.; RINALDI C. A atividade experimental no ensino de ciências naturais: contribuições e contrapontos. Experiências em Ensino de Ciências. v.13, n.1

CRUZ, D. A. Atividades prático-experimentais: tendências e perspectivas. Dia a dia educação. Londrina 2008.

GALIAZZI, M. C. et al. Objetivos das atividades experimentais no ensino médio: a pesquisa coletiva como modo de formação de professores de ciências. Ciência \& Educação, v.7, n.2, p.249-263, 2001.

HAHN, J. C.; MACHADO, E.J. A importância do projeto político pedagógico na educação escolar. São Paulo, 2006. Disponível em: http://coral.ufsm.br/gpforma/2senafe/PDF/068e4.pdf. Acesso em: 22 jul. 2019.

MORAIS, Marta Bouissou; ANDRADE, Maria Hilda de Paiva. Ciências: ensinar e aprender, anos iniciais do ensino fundamental. Belo Horizonte: Dimensão, 2010.

NATIVIDADE, J. S; MEDEIROS, S. A. PROJETO POLÍTICO PEDAGÓGICO E GESTÃO DEMOCRÁTICA: Limites e desafios. Revista Episteme Tranversalis. V. 7, N. 2, 2014.

Psillos, D. e Niedderer, H. (2002). Issues and questions regarding the effectiveness of labwork. Em: Psillos, D. e Niedderer, H. Teaching and learning in the science laboratory. Dordrecht: Kluwer Academic Publishers, p.21-30.

POLADIAN, Marina Lopes Pedrosa. Estudo sobre o programa Residência Pedagógica da UNIFESP: Uma aproximação entre universidade e escola. Pontifícia Universidade Católica de São Paulo.

SERAFIM, M.C. A Falácia da Dicotomia Teoria-Prática. Rev. Espaço Acadêmico, n. 7, 2001. Disponível em: https://pt.scribd.com/document/38035516/A-falacia-da-dicotomia-TeoriaPratica. Acesso em: 20 jul. 2019.

SILVA, M.G.L.; NEVES, L. S. Instrumentação para o ensino de química I. Natal: EDUFRN, 2006.

SOUZA, I.C. A importância da aula prática no laboratório de biologia: ferramenta formativa no processo de ensino aprendizagem de alunos do curso técnico em análises clínicas em Floriano/PI in: III CONGRESSO NACIONAL DE EDUCAÇÃO - CONEDU. 2016. Disponível em: http://www.editorarealize.com.br/revistas/conedu/trabalhos/TRABALHO_EV056_MD1_SA1 8_ID4283_08072016140917.pdf. Acesso em 20 jul. 2019.

VEIGA, RESENDE. Escola: Espaço do Projeto Político Pedagógico. 13. ed. Campina - SP: Papirus, 1998. 
PANIZZOLO, C. SILVA, J. L. SILVESTRE, M. A. GOMES, M. O. JARDIM, V. L. Programa de residência pedagógica da unifesp: Avanços e desafios para a implantação de propostas

Inovadoras de estágio. XVI ENDIPE - ENCONTRO NACIONAL DE DIDÁTICA E PRÁTICAS DE ENSINO. 2012. UNICAMP - Campinas.

POLADIAN, M. L. P. Estudo sobre o programa de residência pedagógica da unifesp: uma aproximação entre universidade e escola. Anais... XI CONGRESSO NACIONAL DE EDUCAÇÃO - EDUCERE. 2013. Pontifícia Universidade Católica do Paraná - Curitiba.

ZIMMERMANN, L. A importância dos laboratórios de ciências para alunos da

Terceira série do ensino fundamental. 2005. Dissertação (de Mestrado em Educação em Ciências e Matemática) - Pontifícia Universidade Católica do Rio Grande do Sul, 2005. 